\title{
Determination of Corn Nutrient Status under N\&K Stressed Condition Using Hyperspectral Analysis
}

\author{
Haihua Wang, Minzan $\mathrm{Li}^{*}$, and Yane Zhang \\ College of Information and Electrical Engineering, China Agricultural University, \\ Beijing 100083, P.R. China \\ \{wanghaihua, gpac, zye\} @cau.edu.cn
}

\begin{abstract}
Variable fertilization for crops, like corn, depends on monitoring nutrition condition. Thus, hyperspectral reflectance was used to predict chlorophyll and total nitrogen content under different $\mathrm{N}, \mathrm{K}$ treatments during corn growth. The area of the experimental field was divided into 3 strips with different nitrogen treatment $(\mathrm{N} 1: 0 \mathrm{~kg} / \mathrm{ha}-\mathrm{low}, \mathrm{N} 2: 314 \mathrm{~kg} / \mathrm{ha}-$ normal, and $\mathrm{N} 3: 653 \mathrm{~kg} / \mathrm{ha}$-high). In each strip, there were 3 repetitions of 3 potassium treatments( $\mathrm{K} 1: 0 \mathrm{~kg} / \mathrm{ha}-\mathrm{low}, \mathrm{K} 2: 214 \mathrm{~kg} / \mathrm{ha}-$ normal, and $\mathrm{K} 3: 500 \mathrm{~kg} / \mathrm{ha}-\mathrm{high}$ ). The results show that growth stages happened in advance under low nitrogen treatment and reflectance intensity, total $\mathrm{N}$, and chlorophyll content are all largest under $\mathrm{N} 2 \mathrm{~K} 1$ in shooting stage. GNDVI(R2 $=0.88$, RMSE $=0.08$ ) performs well for chlorophyll prediction under N3K2. In addition, MLR has the potential of determination of chlorophyll(R2=0.94, RMSE $=0.02)$ and total $\mathrm{N}(\mathrm{R} 2=0.97$, $\mathrm{RMSE}=0.09)$ in trumpet stage, as well as PLSR for chlorophyll $(\mathrm{R} 2=0.99, \quad \mathrm{SEC}=0.01 ; \mathrm{SEP}=0.09)$ and total $\mathrm{N} \quad(\mathrm{R} 2=0.96$, $\mathrm{SEC}=0.11 ; \mathrm{SEP}=0.47$ ) in trumpet stage.
\end{abstract}

Keywords: Hyperspectral Reflectance, Corn, Nutrient, MLR, PLS.

\section{Introduction}

The corn (Zea mays) is cultivated large scale as significant food and economic plant. More inorganic fertilizers are undertaken to gain higher yield in conventional way, however it has been proved that excessive nitrogen(N) fertilizer will reduce the yield and harm environment. So, it is important to give growers a reasonable advice based on growth nutrition condition.

Since chlorophyll content is related to response to nutrition condition, the traditional fertilization is executed based on observing leaf color. But, in fact, this method is not reliable because growth is under complex conditions. Compared to chemical analysis, optical method is nondestructive and fast. Near infrared spectral technology has been used widely in past decades and proved the potential of prediction of growth condition[1-7]. Tang shows that the contents of chlorophyll and carotenoid are corresponded to spectra[8]. Cheng reports LAI and Chlorophyll can be predicted by the first derivative spectra of corn canopies[9].

${ }^{*}$ Corresponding author.

D. Li and Y. Chen (Eds.): CCTA 2011, Part II, IFIP AICT 369, pp. 302-313, 2012.

(C) IFIP International Federation for Information Processing 2012 
Different treatment of nitrogen $(\mathrm{N})$ and potassium(K) can induce growth nutrition change. This paper described the changes of total nitrogen and chlorophyll content, tested by chemical method, in corn leaves under different match of $\mathrm{N}$ and $\mathrm{K}$, then studied how to use hyperspectral analysis to predict total $\mathrm{N}$ and chlorophyll content. Wang reported that potassium $(\mathrm{K})$ could affect the spectra of corn leaf[10]. Walburg considered that ratio of NIR to red was more advantage than red in $\mathrm{N}$ detection[3]. Cheng found some sensitive wavelength regions in different growth stages under different nutrient treatments (N,P, and K) [9].

\section{Materials and Methods}

\subsection{Experiment Design}

Nongda 86 cultivar was selected as experimental corn and was sowed on April 25, 2009 at Shangzhuang Experimental Station of China Agricultural University, Beijing. Fertility of soil was detected before fertilization control. The area of the experimental field was about 12 ha and was divided into 3 strips with different nitrogen treatment (N1:0 kg/ha-low, N2:314 kg/ha-normal, and N3:653 kg/ha-high). In each strip, there were 3 repetitions of 3 potassium treatments( K1:0 kg/ha-low, K2:214 kg/ha-normal, and $\mathrm{K} 3: 500 \mathrm{~kg} / \mathrm{ha}$-high). So the total number of samples was 54 . In addition, water and other fertilizers were treated under normal condition.

\section{$2.2 \quad$ Spectra}

Spectra was obtained under no wind condition between 10:00 and 13:00 and the dates were related to corn growth stages(Table 1). Trumpet and anthesis-silking stage were illustrated in Figure 1a and $1 \mathrm{~b}$ respectively.

Table 1. Growth stages of corn (2009)

\begin{tabular}{|c|c|c|c|c|c|c|c|}
\hline Stage No. & 1 & 2 & 3 & 4 & 5 & 6 & 7 \\
\hline Name & Seedling & & hootin & & Trumpet & Anthesis-silking & Filling \\
\hline Date & $5-27$ & $6-02$ & $6-11$ & $6-23$ & 6-30 & $7-07$ & $7-15$ \\
\hline
\end{tabular}

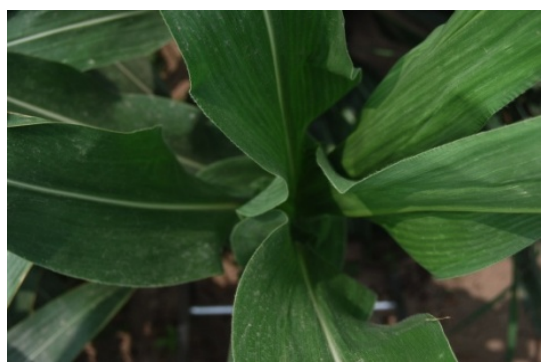

(a)

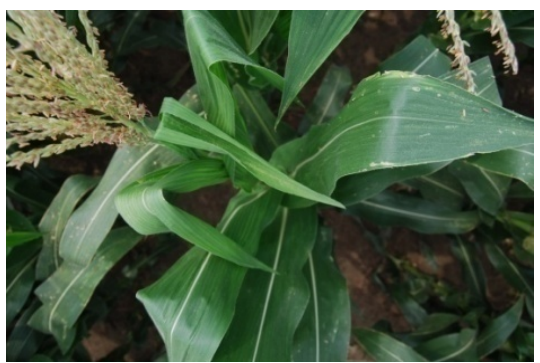

(b)

Fig. 1. Images of (a) Trumpet stage and (b)Anthesis-silking stage 
FieldSpec spectrometer (ASD Co., USA) was used to obtain reflectance spectra which covered from 325 to $1075 \mathrm{~nm}$ with $1 \mathrm{~nm}$ resolution. Spectra were collected in the middle part of the fourth(up to down) corn leaves. Three repetitions for each leaf were averaged for data processing. The standard white board was used as reference for each 3 leaves by equation (1):

$$
\mathrm{R}=\left(\mathrm{R}_{\mathrm{S}}-\text { Dark }\right) /\left(\mathrm{R}_{\mathrm{W}}-\text { Dark }\right),
$$

where $R_{S}$ is reflectance of corn leaf; $R_{W}$ is reflectance of the standard white board; and Dark means that no light enters the spectrometer. Considered that nitrogen may shift in filling stage, data was sampled from ear leaves.

\subsection{Determination of Chlorophyll and Total Nitrogen Content}

The same leaves were packaged with plastic bags for determination of chlorophyll and total nitrogen content after spectra collection. Chemical experiment and SP-2102 UV spectrophotometer (Cany Precision Instruments Co., Ltd, Shanghai China) were used together for chlorophyll content. After veins in leaf were removed, leaf was cut into small fragments. Then $0.4 \mathrm{~g}$ fragments and $25 \mathrm{ml}$ solution with 1 for $95 \%$ ethanol and 2 for $99 \%$ acetone were mixed in a test tube. 24 hours later, the chlorophyllcontaining solution was put into the spectrophotometer and A645, A652 and A663 readings were recorded for calculate the chlorophyll content by equation (2):

$$
\mathrm{C}_{\mathrm{T}}=20.29 \mathrm{~A} 645+8.05 \mathrm{~A} 663 \text { or } \mathrm{C}_{\mathrm{T}}=20.29 \mathrm{~A} 652 \text {, }
$$

where $\mathrm{C}_{\mathrm{T}}$ is a response value to total chlorophyll content (mg . $\mathrm{L}^{-1}$ ). The equation (3):

$$
\mathrm{Chl}=\mathrm{C}_{\mathrm{T}} \cdot \mathrm{V} \times 10^{-3} / \mathrm{W},
$$

was used calculate chlorophyll content $\mathrm{Chl}\left(\mathrm{mg} \cdot \mathrm{g}^{-1}\right)$, where $\mathrm{V}$ is volume of extract liquor, $25 \mathrm{ml}$; $\mathrm{W}$ is fresh weight of leaf, $0.4 \mathrm{~g}$.

To total nitrogen detection, rest fragments were dried in oven and grinded into powder. $0.4 \mathrm{~g}$ powder and $6.2 \mathrm{~g} \mathrm{CuSO} \cdot 5 \mathrm{H}_{2} \mathrm{O}$ were mixed, then reacted with $60 \mathrm{ml}$ concentrated sulfuric acid in a tube. The tube was heat at $500^{\circ} \mathrm{C}$ for 2 hours, then was cooled. Kjeldahl (FOSS NIRSystems, Inc., US) was used to determinate total nitrogen content $\left(\mathrm{mg} \mathrm{g}^{-1}\right)$ of the leaf in solution.

\subsection{PLSR Analysis and Multiple Linear Regression}

$\log (1 / \mathrm{R})$ was often used as absorbance for spectral preprocessing. First and second derivative were also taken into eliminate the baseline drift error. Compared the derivative spectra of high and low total $\mathrm{N}$ content, we selected a set of G, R, NIR wavelengths. Then single-band spectra and some VIs(Vegetable Indexes), like red edge slope, NDVI, GNDIV, DVI, RVI and SVI, were used to predict chlorophyll and total nitrogen content. 
MLR(Multi Linear Regression) and PLSR (PLS Regression) were also introduced to determinate chlorophyll and total nitrogen content in this paper, which were all multivariate data processing methods and fit to hyper spectra. PLS (Partial Least Squares) was based on MLR and PCA (Principle Component Analysis), and PCA had the potential for dimension reduction under considerable variables. So, PLSR was more powerful to calibrate spectrum data than MLR. However, Over-fitting can happen to validation sometimes. In this paper, MATLAB (Math Works Inc., Natick, MA, USA) was used for data processing tool.

\section{Result and Discussion}

\subsection{Chlorophyll and Total Nitrogen Content}

Figure 2 and 3 show chlorophyll and total $\mathrm{N}$ content under different $\mathrm{N}$ treatments in different growth stages respectively. Chlorophyll content increased early, then decreased. Total $\mathrm{N}$ content had the same change as Chlorophyll, but increased again in filling stage(July 15) for the reason that corn steps into reproductive growth.

To low nitrogen treatment, the chlorophyll content reach highest in early shooting stage(June, 11), and the total content decreased at shooting stage(June 23). The same growth stages happen in advance for low nitrogen treatment. Under low nitrogen treatment, the high $\mathrm{N}$ content in filling stage also proved that grain is difficult to get more nitrogen nutrient. In addition, Figure 2 and 3 indicated that the total $\mathrm{N}$ content under high $\mathrm{N}$ treatment deceased later than chlorophyll content, and later than normal $\mathrm{N}$ treatment.

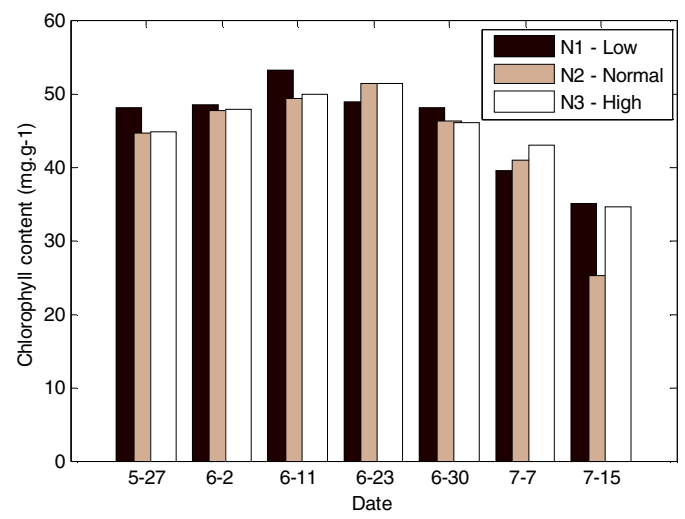

Fig. 2. Chlorophyll content in each stage under different nitrogen treatments 


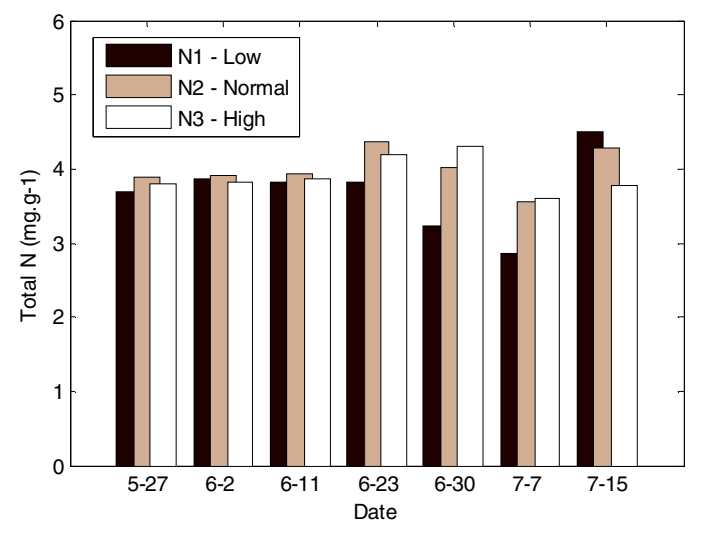

Fig. 3. Total $\mathrm{N}$ content in each stage under different nitrogen treatments

Different NK treatments were studied in-depth except low nitrogen treatment, which showed growth ahead and poor performance of nitrogen absorption in filling stage based on the above analysis. Figure 4 and 5 show that total $\mathrm{N}$ and chlorophyll content of leaves under N2K1 in the shooting stage are highest. Followed by N3K3 and other normal $\mathrm{N}$, the lowest under $\mathrm{N} 3 \mathrm{~K} 2$ and $\mathrm{N} 3 \mathrm{~K} 1$. It can be concluded that normal nitrogen treatment is fit to low potassium and high nitrogen needs high potassium.

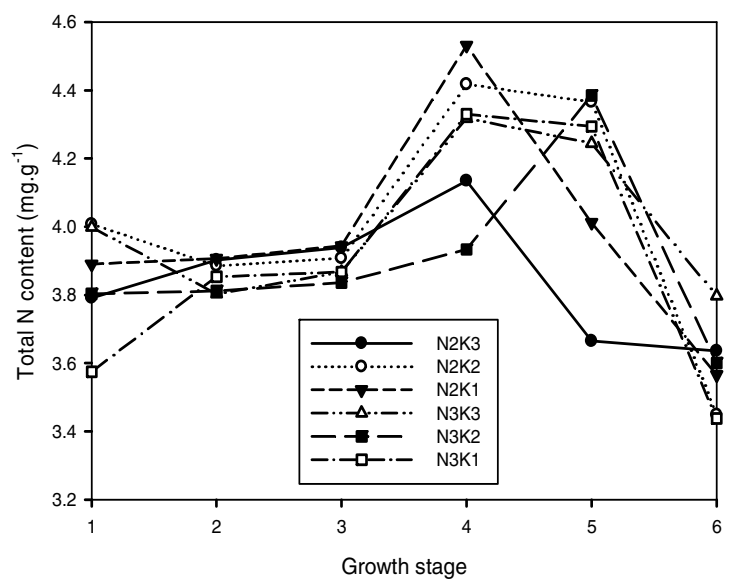

Fig. 4. Total $\mathrm{N}$ content in each stage under different $\mathrm{N}, \mathrm{K}$ treatments 


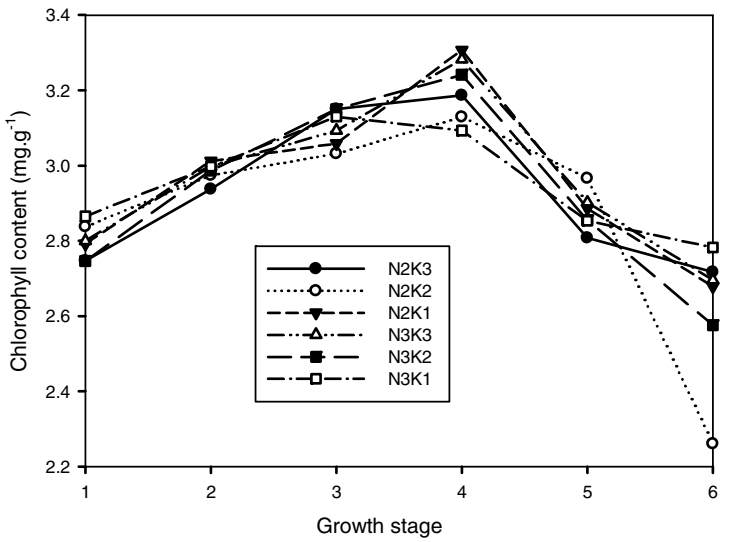

Fig. 5. Chlorophyll content in each stage under different N,K treatments

\subsection{Correlation between Total N Content and Chlorophyll Content}

Total nitrogen content and chlorophyll content of leaf showed low correlation at different growth stages. In Figure. 6 and 7 , the top two performances happened in shooting stage $\left(\mathrm{R}^{2}=0.83\right.$; RMSE $\left.=0.10\right)$ with positive correlation and trumpet stage $\left(\mathrm{R}^{2}=0.69 ; \mathrm{RMSE}=0.27\right)$ with negative correlation.

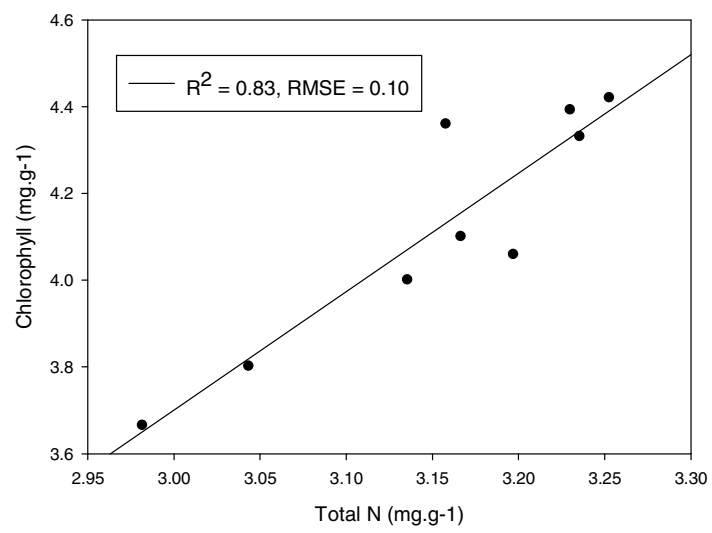

Fig. 6. Correlation between total $\mathrm{N}$ and chlorophyll at Shooting stage (June 23) 


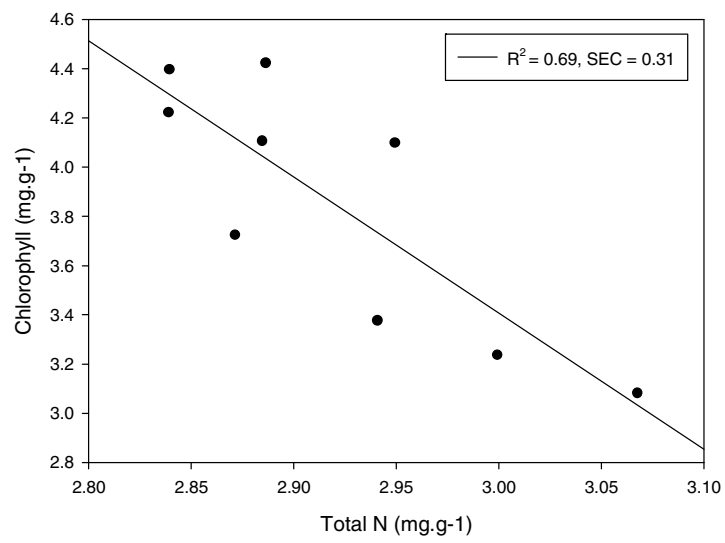

Fig. 7. Correlation between total $\mathrm{N}$ and chlorophyll at Trumpet stage (June 30)

The correlation coefficient between total $\mathrm{N}$ content and chlorophyll content was given in Table 2, excluding filling stage where they are significant different. Three treatments, where the correlation was higher than 0.8 , are N1K3(R2 $=0.83$; RMSE = $0.15), \mathrm{N} 2 \mathrm{~K} 1(\mathrm{R} 2=0.81 ; \mathrm{RMSE}=0.12)$, and N2K3(R2 = 0.81; RMSE $=0.07)$. Under low N,K treatment, although growth stage was earlier, the correlation of chlorophyll and total $\mathrm{N}$ was higher. In contrast, high nitrogen treatments had low correlation, which indicated that excess nitrogen would affect transform nitrogen to chlorophyll.

Table 2. Correlation between total $\mathrm{N}$ and Chlorophyll under different treatments

\begin{tabular}{ccc}
\hline $\mathrm{N}, \mathrm{K}$ treatment & $\mathrm{R} 2$ & $\mathrm{RMSE}$ \\
\hline $\mathrm{N} 1 \mathrm{~K} 3$ & 0.83 & 0.15 \\
$\mathrm{~N} 1 \mathrm{~K} 2$ & 0.78 & 0.19 \\
$\mathrm{~N} 1 \mathrm{~K} 1$ & 0.31 & 0.32 \\
$\mathrm{~N} 2 \mathrm{~K} 3$ & 0.81 & 0.07 \\
$\mathrm{~N} 2 \mathrm{~K} 2$ & 0.67 & 0.19 \\
$\mathrm{~N} 2 \mathrm{~K} 1$ & 0.81 & 0.12 \\
$\mathrm{~N} 3 \mathrm{~K} 3$ & 0.24 & 0.18 \\
$\mathrm{~N} 3 \mathrm{~K} 2$ & 0.06 & 0.23 \\
$\mathrm{~N} 3 \mathrm{~K} 1$ & 0.22 & 0.29 \\
\hline
\end{tabular}

\subsection{Leaf Spectrum}

Typical spectra of corn leaves (Anthesis-silking stage; The sample S5, total $\mathrm{N}=$ 4.1234\%; S26, total $\mathrm{N}=2.0707 \%$ ) are illustrated in Figure. 8. Wavelength ranges below 405 and above 978 were cut with high noise. In the visible region, most of the light was absorbed and there was a small peak in $553 \mathrm{~nm}$ related to green band. The spectra curve jump to strong reflectance in near-infrared region through red edge $(685 \sim 750 \mathrm{~nm})$, which can be related to the internal organizational structure of corn leaf. 


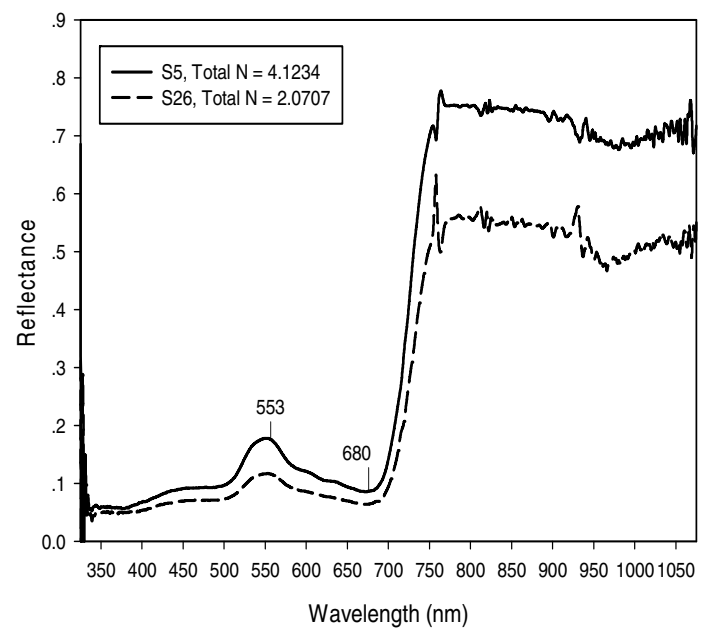

Fig. 8. Reflectance spectra of two corn leaves with high and low total $\mathrm{N}$ content

Figure 9 and 10 show spectral reflectance at 553 and $818 \mathrm{~nm}$ under different $\mathrm{N}, \mathrm{K}$ treatments in different stages respectively. Overall, changes of reflectance intensity are like wave, and there are two peaks in the shooting stage(Stage 4) and anthesissilking(Stage 6) stage. The reflectance intensity at $553 \mathrm{~nm}$ is lowest in trumpet stage(Stage 5).

$\mathrm{N} 2 \mathrm{~K} 1, \mathrm{~N} 3 \mathrm{~K} 3$ were more strong and N3K2, N2K3, N1K2 were lower in shooting stage at both wavelength. It was similar to the result of leaf total $\mathrm{N}$ content and chlorophyll content. Compared to other $\mathrm{N}, \mathrm{K}$ treatments, the intensity of reflectance under N2K1, N3K2 change obviously in trumpet and anthesis-silking stage(Stage 6). High nitrogen treatments increased gradually, and low nitrogen treatment declined in general.

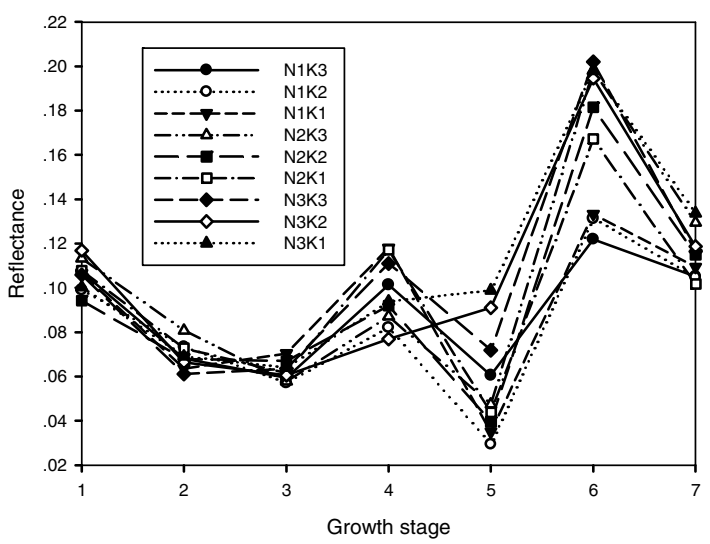

Fig. 9. Reflectance in each stage at $553 \mathrm{~nm}$ 


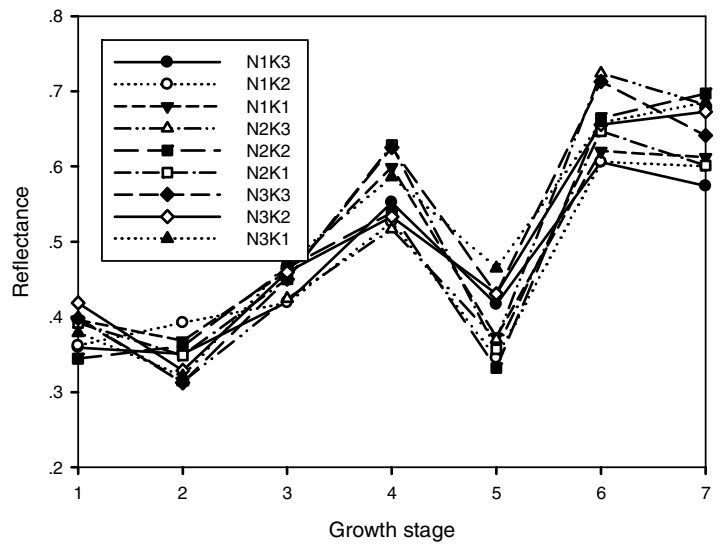

Fig. 10. Reflectance in each stage at $818 \mathrm{~nm}$

\subsection{Wavelength Selection and VIs Regression}

Figure 11 shows Second derivative spectra of $\log (1 / \mathrm{R})$ of the same corn leaves shown in Figure 8. 553,680,760 and 818nm were selected as green, red, red edge, and nearinfrared wavelengths.

Single-band spectra and some VIs, like red edge slope, NDVI, GNDIV, DVI, RVI and SVI, were used to predict chlorophyll and total nitrogen content. The best performance was the correlation between $\operatorname{GNDVI}\left(\mathrm{R}^{2}=0.88, \mathrm{RMSE}=0.08\right)$ and chlorophyll content under N3K2, followed by $\mathrm{G}\left(\mathrm{R}^{2}=0.79\right.$, RMSE $\left.=0.13\right)$ under N2K2 and NDVI $\left(R^{2}=0.78\right.$, RMSE $\left.=0.11\right)$ under N3K2.

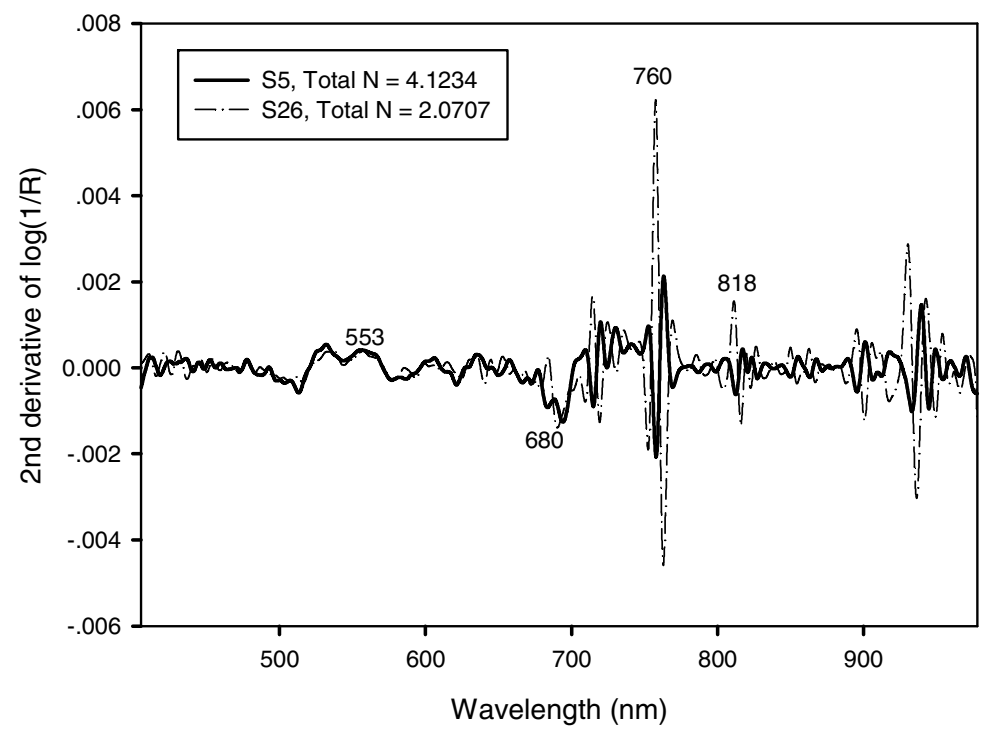

Fig. 11. Second derivative spectra of $\log (1 / \mathrm{R})$ of the same corn leaves shown in Figure 8 
To total N, all top 3 performances happened in anthesis-silking stage(Stage 6), including $\mathrm{G}\left(\mathrm{R}^{2}=0.88, \mathrm{RMSE}=0.12\right), \mathrm{R}\left(\mathrm{R}^{2}=0.83, \mathrm{RMSE}=0.14\right)$ and GDNVI $\left(\mathrm{R}^{2}\right.$ $=0.81, \mathrm{RMSE}=0.15$ ) respectively.

\subsection{PLSR for Total N and Chlorophyll Content}

Some efficient results is shown in Table 3 by PLSR for total $\mathrm{N}$ and chlorophyll content in different growth stage. Better performances for Chlorophyll content were shooting stage $\left(\mathrm{R}^{2}=0.95, \mathrm{SEC}=0.03\right.$; $\left.\mathrm{SEP}=0.12\right)$ and trumpet stage $\left(\mathrm{R}^{2}=0.99\right.$, $\mathrm{SEC}=0.01 ; \mathrm{SEP}=0.09)$ respectively. Better results for total $\mathrm{N}$ content were filling stage $\left(\mathrm{R}^{2}=1.00, \mathrm{SEC}=0.02 ; \mathrm{SEP}=0.58\right)$ and trumpet stage $\left(\mathrm{R}^{2}=0.96, \mathrm{SEC}=\right.$ 0.11 ; SEP $=0.47$ ) respectively. Compare the four results, prediction for total $\mathrm{N}$ content is not perfect with high SEP in validation. In addition, The PLSR results for total $\mathrm{N}$ and chlorophyll content under different $\mathrm{N}, \mathrm{K}$ treatment are good for calibration, but over-fitting for validation.

In general, total $\mathrm{N}$ and chlorophyll content can be predicted in trumpet and shooting stage using reflectance spectra for assessment of corn nutrition condition.

Table 3.PLSR for total $\mathrm{N}$ and chlorophyll content in different growth stage (5 factors)

\begin{tabular}{|c|c|c|c|c|c|c|c|c|c|}
\hline \multicolumn{6}{|c|}{ Chlorophyll content } & \multicolumn{4}{|c|}{ Total $N$ content } \\
\hline \multirow[t]{2}{*}{ Stage } & \multicolumn{2}{|c|}{ Calibration } & \multicolumn{2}{|c|}{ Validation } & \multirow[t]{2}{*}{ Stage } & \multicolumn{2}{|c|}{ Calibration } & \multicolumn{2}{|c|}{ Validation } \\
\hline & $\mathrm{R} 2$ & SEC & $\mathrm{R} 2$ & SEP & & $\mathrm{R} 2$ & SEC & $\mathrm{R} 2$ & SEP \\
\hline Shooting & 0.95 & 0.03 & 0.71 & 0.12 & Trumpet & 0.96 & 0.11 & 0.72 & 0.47 \\
\hline Trumpet & 0.99 & 0.01 & 0.70 & 0.09 & Filling & 1.00 & 0.02 & 0.53 & 0.58 \\
\hline
\end{tabular}

\subsection{MLR Analysis for Total N and Chlorophyll Content}

The intensity of $\log (1 / \mathrm{R})$ at $\mathrm{R}, \mathrm{G}, \mathrm{NIR}$, and the slope of red edge were selected to implement MLR to predict total $\mathrm{N}$ and chlorophyll content. The result is described in Table 4 . The best correlation $\left(\mathrm{R}^{2)}\right.$ for chlorophyll content prediction was 0.94 (RMSE $=0.02)$, and for total $\mathrm{N}$ content was $0.97(\mathrm{RMSE}=0.09)$ in trumpet stage $($ June 30$)$.

Table 4. MLR for $\mathrm{N}$ and chlorophyll content in different growth stage

\begin{tabular}{ccccc}
\hline Date & $\begin{array}{c}\mathrm{R}^{2} \text { for } \\
\text { Chlorophyll }\end{array}$ & SEC & $\begin{array}{c}\mathrm{R}^{2} \text { for } \\
\text { total N }\end{array}$ & SEC \\
\hline $5-27$ & 0.72 & 0.07 & $\underline{\mathbf{0 . 2 6}}$ & 0.13 \\
$6-02$ & 0.54 & 0.02 & 0.66 & 0.04 \\
$6-11$ & 0.79 & 0.05 & 0.89 & 0.02 \\
$6-23$ & 0.75 & 0.05 & 0.78 & 0.13 \\
$6-30$ & $\mathbf{0 . 9 4}$ & 0.02 & $\mathbf{0 . 9 7}$ & 0.09 \\
$7-07$ & 0.51 & 0.14 & 0.92 & 0.10 \\
$7-15$ & $\underline{\mathbf{0 . 4 8}}$ & 0.23 & 0.60 & 0.21 \\
\hline
\end{tabular}


Table 5 shows that the best correlation $\left(\mathrm{R}^{2)}\right.$ for chlorophyll content prediction is $0.96(\mathrm{RMSE}=0.04)$ under N3K3 treatment, and for total $\mathrm{N}$ content is $0.99(\mathrm{RMSE}=$ 0.04 ) under N3K1 treatment.

Table 5. MLR for $\mathrm{N}$ and chlorophyll content under different $\mathrm{N}, \mathrm{K}$ treatment

\begin{tabular}{ccccc}
\hline $\begin{array}{c}\mathrm{N} / \mathrm{K} \\
\text { treatment }\end{array}$ & $\begin{array}{c}\mathrm{R}^{2} \text { for } \\
\text { Chlorophyll }\end{array}$ & $\mathrm{SEC}$ & $\begin{array}{c}\mathrm{R}^{2} \text { for total } \\
\mathrm{N}\end{array}$ & $\mathrm{SEC}$ \\
\hline $\mathrm{N} 1 \mathrm{~K} 3$ & 0.85 & 0.09 & 0.91 & 0.11 \\
$\mathrm{~N} 1 \mathrm{~K} 2$ & 0.78 & 0.17 & 0.81 & 0.17 \\
$\mathrm{~N} 1 \mathrm{~K} 1$ & $\underline{\mathbf{0 . 5 9}}$ & 0.12 & 0.68 & 0.22 \\
$\mathrm{~N} 2 \mathrm{~K} 3$ & 0.61 & 0.12 & $\underline{\mathbf{0 . 5 0}}$ & 0.12 \\
$\mathrm{~N} 2 \mathrm{~K} 2$ & 0.88 & 0.10 & 0.92 & 0.09 \\
$\mathrm{~N} 2 \mathrm{~K} 1$ & 0.80 & 0.09 & 0.76 & 0.14 \\
$\mathrm{~N} 3 \mathrm{~K} 3$ & $\mathbf{0 . 9 6}$ & 0.04 & 0.93 & 0.05 \\
$\mathrm{~N} 3 \mathrm{~K} 2$ & 0.94 & 0.06 & 0.85 & 0.09 \\
$\mathrm{~N} 3 \mathrm{~K} 1$ & 0.82 & 0.05 & $\mathbf{0 . 9 9}$ & 0.04 \\
\hline
\end{tabular}

\section{Conclusion}

Chlorophyll and total $\mathrm{N}$ content increased early, then decreased until filling stage when reproductive growth started. The correlation between Chlorophyll and total $\mathrm{N}$ content was analyzed because growth stages happened in advance under low nitrogen treatment. Chlorophyll and total $\mathrm{N}$ content under the treatments of normal nitrogen and low potassium performed best in shooting stage, which means high nitrogen is not necessary.

Reflectance under $\mathrm{N} 2 \mathrm{~K} 1$ and $\mathrm{N} 3 \mathrm{~K} 3$, similar to total $\mathrm{N}$ content and chlorophyll content, were more strong than N3K2, N2K3,N1K2 in shooting stage at both 553 and $818 \mathrm{~nm}$ wavelength. GNDVI $\left(\mathrm{R}^{2}=0.88, \mathrm{RMSE}=0.08\right)$ was better than other VIs for prediction of chlorophyll content under N3K2, as well as $\mathrm{G}\left(\mathrm{R}^{2}=0.88, \mathrm{RMSE}=0.12\right)$ was better for total $\mathrm{N}$ content prediction in anthesis-silking stage. In trumpet stage, the correlation of Multiple Linear Regression(553, 680, 760 and 818) for prediction of Chlorophyll and total $\mathrm{N}$ content are 0.94(RMSE $=0.02)$ and $0.97(\mathrm{RMSE}=0.09)$ respectively, and PLSR also had good performance for total $\mathrm{N}$ content $\left(\mathrm{R}^{2}=0.96\right.$, $\mathrm{SEC}=0.11$; $\mathrm{SEP}=0.47)$ and chlorophyll content $\left(\mathrm{R}^{2}=0.95, \mathrm{SEC}=0.03\right.$; $\mathrm{SEP}=$ 0.12). In a word, total $\mathrm{N}$ and chlorophyll content can be predicted in trumpet and shooting stage or some $\mathrm{N}, \mathrm{K}$ treatments using reflectance spectra for assessment of corn nutrition condition.

Acknowledgments. This study was supported by Chinese National Programs for High Technology Research and Development Research Fund (2011AA100703) and NSFC Programs of China (U0931001). 


\section{References}

1. Norris, K.H.: Design and development of a new moisture meter. Agric. Eng. 45, 370 (1964)

2. Gausman, H.W., Allen, W.A.: Optical Parameters of Leaves of 30 Plant Species. Plant Physiology 52, 57-62 (1973)

3. Walburg, G., Bauer, M.E., Daughtry, C.S.T.: Effect of Nitrogen Nutrition on Growth, Yield and Reflectance Characteristics of Corn Canopies. Agronomy Journal 74, 677-683 (1982)

4. Shibayama, M., Akiyama, T.A.: A Spectroradiometer for Field Use: V I. Radiometric Estimation for Chlorophyll Index of Rice Canopy. Japanese Journal of Crop Science 55(4), 433-438 (1986)

5. Yan, Y.-L.: Near-Infrared Spectrum Analysis and Application, p. 518. China Light Industry Press, Beijing (2005)

6. Li, M.-Z.: Spectral Analysis Technology and Application, p. 45. Science Press, Beijing (2006)

7. Wang, J.-H., Zhao, C.-J., Huang, W.-J.: Remote Sensing Quantitative Theory and Application in Agriculture. Science Press, Beijing (2008)

8. Tang, Y.-L., Huang, J.-F., Wang, X.-Z.: Study on hyper Spectral characteristics of corn leaves and their correlation to chlorophyll and carotenoid. Journal of Maize Sciences 16(2), 71 (2008)

9. Cheng, Y., Hu, C., Wang, C., Yu, G.: Physiological response and spectral characteristics of summer corn under nutrient stress condition. Resources Science 23(6), 54-58 (2003)

10. Wang, L., Bai, Y.: Nutrients Change and Spectral Response of Spring Corn Leaf for Varying Amounts of Potassium Fertilization. Journal of Remote Sensing 11(5), 641-647 (2007) 